\title{
Expression of ALK1 and p80 in Inflammatory Myofibroblastic Tumor and Its Mesenchymal Mimics: A Study of 135 Cases
}

Melissa H. Cessna, M.D., Holly Zhou, M.D., Warren G. Sanger, Ph.D., Sherrie L. Perkins, M.D., Ph.D., Sheryl Tripp, M.T., Diane Pickering, M.S., Clark Daines, M.D., Cheryl M. Coffin, M.D.

Department of Pathology, Primary Children's Medical Center and University of Utah School of Medicine, Salt Lake City, Utah (MHC, HZ, SLP, ST, CD, CMC); and Department of Pediatrics, University of Nebraska Medical Center, Omaha, Nebraska (WGS, DP)

Abnormalities of chromosome 2p23 with expression of ALK1 and p80 occur in both inflammatory myofibroblastic tumor (IMT) and anaplastic large cell lymphoma. This immunohistochemical study investigates whether the $A L K$ family of neoplasms includes fibroblastic-myofibroblastic, myogenic, and spindle cell tumors. Formalin-fixed paraffinembedded archival tissues from 10 IMTs and 125 other soft tissue tumors were stained for ALK1 and p80 with standard immunohistochemistry. ALK1 and/or $\mathrm{p} 80$ reactivity was observed in a cytoplasmic pattern in IMT $(4 / 10 ; 40 \%)$, malignant peripheral nerve sheath tumor $(4 / 10 ; 40 \%)$, rhabdomyosarcoma $(6 / 31 ; 19 \%)$, leiomyosarcoma $(1 / 10 ; 10 \%)$, and malignant fibrous histiocytoma $(1 / 11 ; 9 \%)$. No staining was observed in nodular fasciitis, desmoid, infantile myofibromatosis, infantile fibrosarcoma, synovial sarcoma, leiomyoma, or myofibrosarcoma. Alveolar rhabdomyosarcomas $(4 / 16 ; 25 \%)$ displayed a distinctive dot-like cytoplasmic positivity. No cases displayed nuclear reactivity. Fluorescent in situ hybridization on 12 of the positive cases revealed a combination of abnormalities including $A L K$ break-apart signals, nucleophosmin (NPM)/ $A L K$ fusions, or extra copies of $2 \mathrm{p} 23$. This study demonstrates that in addition to IMT, abnormalities of ALK1 and p80 expression with a variety of structural chromosomal changes are found in several sarcomas, especially rhabdomyosarcoma and malignant peripheral nerve sheath tumor. Although immunoreactivity in non-IMTs cannot distinguish

Copyright (C) 2002 by The United States and Canadian Academy of Pathology, Inc.

VOL. 15, NO. 9, P. 931, 2002 Printed in the U.S.A

Date of acceptance: May 20, 2002.

Presented in part at the United States and Canadian Academy of Pathology, Atlanta, GA, on March 8, 2001.

Address correspondence to: Cheryl M. Coffin, M.D., Department of Pathology, University of Utah School of Medicine, 50 North Medical Drive, Salt Lake City, UT 84132; e-mail: pcccoffi@ihc.com; fax: 801-588-3169.

DOI: 10.1097/01.MP.0000026615.04130.1F between structural abnormalities involving 2 p23 or additional copies of $2 \mathrm{p} 23$, it supports the concept of $A L K$ involvement in a larger group of neoplasms, some of which have other documented clonal abnormalities. In IMT, immunohistochemistry for ALK1 and p80 is useful as an indicator of a 2p23 abnormality, but it must be interpreted in the context of histologic and other clinicopathologic data if used as an adjunct to differential diagnosis.

KEY WORDS: $A L K$ gene rearrangements, ALK immunohistochemistry, Anaplastic large cell lymphoma, Inflammatory myofibroblastic tumor.

Mod Pathol 2002;15(9):931-938

Inflammatory myofibroblastic tumor (IMT), a tumor of myofibroblastic spindle cells accompanied by a lymphoplasmacytic and eosinophilic inflammatory infiltrate, and anaplastic large cell lymphoma share clonal aberrations involving the short arm of chromosome 2 in region p21-p23 (1-5). Chromosome 2p23 is the site of the human $A L K$ gene, which codes for anaplastic lymphoma kinase, a tyrosine kinase receptor and member of the insulin growth factor receptor superfamily. Antibodies to the protein product of the $A L K$ gene detect both $A L K$ expression associated with 2p23 rearrangements and other abnormalities in $A L K$ deregulation.

$A L K$ rearrangements and/or ALK1 and p80 immunoreactivity have been reported in $36-60 \%$ of IMTs and $8-33 \%$ of "inflammatory pseudotumors" $(3,5,6-9)$. Fusion oncogenes have been identified in a small proportion of IMTs with $A L K$ rearrangements and include TPM3-ALK and TPM4-ALK (4). In anaplastic large cell lymphoma, the clonal abnormalities of $A L K$ include a characteristic translocation $\mathrm{t}(2,5)(\mathrm{p} 23 ; \mathrm{q} 35)$, variant translocations, and a TPM3-ALK fusion oncogene in some cases $(2,10-$ 15). Various investigators have shown that $A L K$ gene rearrangements and $A L K$ expression are found 
in cell lines of neuroblastoma, neuroectodermal tumors, malignant melanoma, small cell lung carcinoma, and rhabdomyosarcoma and in central nervous system tissue $(12,15)$. Thus, it appears that structural or functional abnormalities of the $A L K$ gene are found in a group of mesenchymal neoplasms including anaplastic large cell lymphoma, IMT, and possibly others.

The purpose of this study is to systematically investigate by immunohistochemical means, with selective fluorescence in situ hybridization (FISH) analysis, whether the $A L K$ family of tumors, whose current members are IMT and anaplastic large cell lymphoma, also includes mesenchymal tumors with a predominantly spindle cell phenotype and rhabdomyosarcoma.

\section{MATERIALS AND METHODS}

\section{Case Selection}

Formalin-fixed, paraffin-embedded archival tissue was obtained from institutional and consultation files. Cases included 10 IMTs and 125 small round blue cell and spindle cell tumors. These included 31 rhabdomyosarcomas, 10 nodular fasciitides, 10 desmoid-type fibromatoses, 10 infantile myofibromatoses, 10 infantile fibrosarcomas, 11 malignant fibrous histiocytomas, 10 synovial sarcomas, 10 malignant peripheral nerve sheath tumors, 3 myofibrosarcomas, 10 leiomyomas, and 10 leiomyosarcomas. The rhabdomyosarcomas included 16 alveolar and 15 embryonal (including 2 anaplastic, 1 spindle cell, and 2 botyroid) types. Soft tissue tumors were classified according to the World Health Organization Classification of Soft Tissue Tumors (16), the International Classification of Rhabdomyosarcoma (17), and published descriptions for myofibrosarcoma (18-20). Clinicopathologic and immunohistochemical findings for some cases of IMT, rhabdomyosarcoma, and infantile fibrosarcoma had been previously published ( 1 , $3,8,21-23)$. Five of 10 IMTs were included in a previous study of ALK-1 and p80 expression and chromosome 2p23 rearrangements (5), and 8 were included in a separate study (8). All specimens were originally diagnosed between 1976 and 2000. All of the inflammatory myofibroblastic tumors, rhabdomyosarcoma, infantile myofibromatoses, infantile fibrosarcomas, and myofibrosarcomas were from children and adolescents. All of the leiomyomas were from adults. The remaining tumors occurred in both children and adults. The original surgical pathology reports were reviewed, and the diagnoses were confirmed by review of hematoxylin and eosin-stained sections and immunohistochemical studies. One representative block for each case was selected for immunohistochemical staining.
Antibodies and Immunostaining

Immunohistochemical studies were performed on $4-\mu \mathrm{m}$-thick formalin-fixed, paraffin-embedded tissue sections, using a standard heat-induced epitope retrieval method, a standard avidin-biotin peroxidase complex detection technique, and an automated immunostainer (Ventana Medical Systems, Tucson, AZ).

The monoclonal ALK1 antibody was obtained from DAKO Company (Carpinteria, CA). ALK1 staining was done after heat-induced epitope retrieval in an electric pressure cooker for 3 minutes (total time in pressure cooker, $30 \mathrm{~min}$ ) in a citrate buffer at $\mathrm{pH}$ 6.0. The antibody was applied at a dilution of 1:25 for 32 minutes using the Ventana Nexus autostainer with a basic diaminobenzidine detection kit, endogenous peroxidase blocking, and staining amplification kit.

The polyclonal $\mathrm{p} 80^{\mathrm{NPM} / \mathrm{ALK}}$ antibody was obtained from Monosan (Leiden, the Netherlands). p80 staining was done after heat-induced epitope retrieval in an electric pressure cooker for 3 minutes (total time in pressure cooker, $30 \mathrm{~min}$ ) in a citrate buffer at $\mathrm{pH}$ 6.0. The antibody was applied at a dilution of 1:30 for 32 minutes using the Ventana Nexus autostainer with a basic diaminobenzidine detection kit, endogenous peroxidase blocking, and staining amplification kit.

Appropriate positive and negative controls were used. Reactivity was interpreted as positive or negative. Positive cases were graded according to the percentage of tumor cells with staining, with $1+$ representing $0-30 \%$ positivity, $2+$ representing $>30-70 \%$ positivity, and $3+$ representing $>70 \%$ positivity. Cases of positive staining were assessed as to the localization of staining to cytoplasm, nucleus, or both of tumor cells. Diffuse cytoplasmic staining of nontumor cell types was not observed.

\section{0 e}

FISH Methods for Detection of $t(2,5)(p 23 ; q 35)$

and Other Rearrangements of 2p23 (ALK), using ALK and NPM/ALK Probes on Paraffin-

Embedded Tumor Tissue

FISH procedures were performed on 4 - to $5-\mu \mathrm{m}$ unstained tissue sections using an NPM/ALK twocolor FISH probe specific for the $\mathrm{t}(2,5)(\mathrm{p} 23 ; \mathrm{q} 35)$ and a two-color, break-apart $A L K$ probe that flanks the $A L K$ gene region at $2 \mathrm{p} 23$ for detection of the alternative rearrangements involving the $A L K$ gene. The NPM/ALK probes were obtained from Dr. Steve Morris, and the $A L K$ break-apart probe is commercially available (Vysis, Downers Grove, IL). Before the hybridization, the slides were pretreated using the VP2000 automated slide processor (Vysis) using the program specified for paraffin slides. Briefly, the program included deparaffinization of the slides, followed by dehydration, $0.2 \mathrm{~N}$ HCL treatment for 
15 minutes, and incubation in sodium thiocyanate for 20 minutes at $80^{\circ} \mathrm{C}$. The slides were then digested in protease for 15 minutes at $37^{\circ} \mathrm{C}$, rinsed, and dehydrated. For FISH, three overlapping chromosome 5 cosmid clones $(13,15-2$, and 47C12) located immediately centromeric to the NPM gene locus and an $A L K \mathrm{P} 1$ clone, which is homologous to the $A L K$ gene locus translocated in the $\mathrm{t}(2,5)$, were labeled by nick translation with Spectrum Green and Spectrum Orange, respectively, and then purified using the Bio-Spin P-30 chromatography column (Bio-Rad, Hercules, CA). For each hybridization, the labeled probes were combined in equal amounts (50 ng each), lyophilized with $1 \mu \mathrm{g}$ of Cot-1 DNA, and resuspended in LSI Hybridization Buffer (Vysis). For the cases that did not exhibit the $\mathrm{t}(2,5)$, the LSI $A L K$ (Vysis) was used according to manufacturer's instruction. For hybridization, 10 $\mu \mathrm{L}$ of the probe mixture was placed on the pretreated tissue section, coverslipped, and sealed. The probe and target DNA were co-denatured at $75^{\circ} \mathrm{C}$ for 5 minutes, followed by an overnight hybridization at $37^{\circ} \mathrm{C}$ using the HybRite automated FISH system (Vysis). After hybridization, the slides were washed for 2 minutes in $2 \times \mathrm{SSC} / 0.1 \% \mathrm{NP}-40$ at $72^{\circ}$ C, followed by 2 minutes in $2 \times \mathrm{SSC} / 0.1 \% \mathrm{NP}-40$ at room temperature. The slides were counterstained with 4', 6-diamidino-2-phenylindole (DAPI) at a concentration of $125 \mathrm{ng} / \mathrm{mL}$ in antifade solution. Analysis was performed on an Olympus BX51 flüorescence microscope equipped with appropriate filters and Cytovision FISH system image capture software (Applied Imaging, Santa Clara, CA). For each case, 100 cells were scored for the presence of the $t(2,5)$ as evidenced by juxtaposition of the red (ALK) and green (NPM) signal forming a yellow "fusion" signal. The false-positive rate for this FISH system, as established by University of Nebraska Medical Center Human Genetics Laboratories before this study, is $0-7 \%$, with cutoff at $12 \%$. For the $A L K$ break-apart probe, the cells were scored for a "separation" of the green and red signal, which is indicative of a rearrangement of the $A L K$ gene region. The false-positive rate for this test is $0-10 \%$, with a cutoff of $15 \%$.

\section{RESULTS}

The immunohistochemical findings are summarized in Tables 1 and 2. Three of 10 IMTs, all from children, showed staining for both ALK1 and p80 (Fig. 1, A-C); one IMT showed expression of only p80. The staining pattern in all of these IMTs was distinctly and diffusely cytoplasmic in single welldefined cells. No cytoplasmic or nuclear staining of nontumor cell types was observed. A fibrillary, submembranous, or punctate quality of the cytoplasmic staining in these IMTs was not discernible.
TABLE 1. ALK1 and p80 Reactivity in Spindle Cell Tumors

\begin{tabular}{lll}
\hline \multirow{1}{*}{\multicolumn{1}{c}{ Diagnosis }} & \multicolumn{2}{c}{$\begin{array}{c}\text { No. Positive }{ }^{a} / \text { No. } \\
\text { Tested }\end{array}$} \\
\cline { 2 - 3 } & ALK & p80 \\
\hline Inflammatory myofibroblastic tumor & $3 / 10$ & $4 / 10$ \\
Rhabdomyosarcoma & $6 / 31$ & $5 / 31$ \\
Malignant peripheral nerve sheath tumor & $2 / 10$ & $4 / 10$ \\
Leiomyosarcoma & $1 / 10$ & $1 / 10$ \\
Malignant fibrous histiocytoma & $1 / 11$ & $1 / 11$ \\
Nodular fasciitis & $0 / 10$ & $0 / 10$ \\
Desmoid fibromatosis & $0 / 10$ & $0 / 10$ \\
Infantile myofibromatosis & $0 / 10$ & $0 / 10$ \\
Infantile fibrosarcoma & $0 / 10$ & $0 / 10$ \\
Myofibrosarcoma & $0 / 3$ & $0 / 3$ \\
Leiomyoma & $0 / 10$ & $0 / 10$ \\
Synovial sarcoma & $0 / 10$ & $0 / 10$ \\
\hline
\end{tabular}

${ }^{a}$ All positive cases displayed cytoplasmic reactivity without nuclear reactivity.

Among the other mesenchymal tumors, no cases of nodular fasciitis, fibromatosis, infantile myofibromatosis, infantile fibrosarcoma, synovial sarcoma, myofibrosarcoma, or leiomyoma showed immunohistochemical reactivity for either ALK1 or p80. Positivity for both ALK1 and p80 was seen in five rhabdomyosarcomas (four alveolar and one embryonal, all from children; Fig. 2, A-C), two malignant peripheral nerve sheath tumors (both from children), one leiomyosarcoma (from a child), and one malignant fibrous histiocytoma (from an adult). Two additional malignant peripheral nerve sheath tumors (one from an adult, one from a child) showed positivity for only p80. One other embryonal rhabdomyosarcoma (from a child) showed positivity for only ALK1. The staining pattern in all but two non-IMTs was diffusely cytoplasmic. Three alveolar rhabdomyosarcomas displayed a distinctive punctate, dot-like pattern of cytoplasmic staining visible at $40-100 \times$. With the exception of the dotlike cytoplasmic reactivity in alveolar rhabdomyosarcomas, the cytoplasmic staining for ALK1 and p80 in non-IMTs was less intense than in IMTs. The non-IMTs with $1+$ positivity displayed a low percentage of reactive cells, $<10 \%$ in 6 of 10 cases. In all of the tumors with both ALK1 and p80 staining, the same types of cells were positive with both markers. Among the rhabdomyosarcomas, primitive round or polygonal cells and rhabdomyoblasts with eccentric nuclei and eosinophilic cytoplasm were positive, and in general, the less differentiated cells appeared to stain more frequently.

The FISH results for ALK1- and/or p80-positive tumors are shown in Table 3. Among the three IMT that could be analyzed, all three had $A L K$ rearrangements with the $A L K$ break-apart probe (two classic splits and one complex variant), and none had an NPM/ALK fusion detected. All of these IMT displayed cytoplasm ALK1 and/or p80 reactivity. Among the six rhabdomyosarcomas that could be 


\begin{tabular}{|c|c|c|c|c|c|c|c|c|}
\hline \multirow{2}{*}{ Histologic Type } & \multicolumn{8}{|c|}{ Staining Frequency and Intensity } \\
\hline & ALK Positive & $1+$ & $2+$ & $3+$ & p80 Positive & $1+$ & $2+$ & $3+$ \\
\hline Inflammatory myofibroblastic tumor & 3 & 0 & 1 & 2 & 4 & 0 & 1 & 3 \\
\hline Alveolar rhabdomyosarcoma & 4 & 1 & 3 & 0 & 4 & 4 & 0 & 0 \\
\hline Embryonal rhabdomyosarcoma & 2 & 2 & 0 & 0 & 1 & 1 & 0 & 0 \\
\hline Malignant peripheral nerve sheath tumor & 2 & 1 & 1 & 0 & 4 & 3 & 1 & 0 \\
\hline Leiomyosarcoma & 1 & 1 & 0 & 0 & 1 & 1 & 0 & 0 \\
\hline Malignant fibrous histiocytoma & 1 & 1 & 0 & 0 & 1 & 1 & 0 & 0 \\
\hline
\end{tabular}

analyzed, one each of embryonal and alveolar subtypes were positive for NPM/ALK and displayed diffuse, weak cytoplasmic ALK1 and/or p80 staining. One embryonal rhabdomyosarcoma with weak cytoplasmic ALK1 and p80 reactivity was negative for $A L K$ rearrangements but had three copies of 2 p23. Three alveolar rhabdomyosarcomas with dot-like cytoplasmic ALK1 and p80 reactivity had either three to six copies of $2 \mathrm{p} 23$ without $A L K$ rearrangements in two cases or had a complex ALK rearrangement with the ALK break-apart probe. One malignant peripheral nerve sheath tumor was positive for NPM/ALK by FISH and was reactive for $\mathrm{p} 80$. One case each of leiomyosarcoma and malignant fibrous histiocytoma had two and four copies of 2p23, respectively, but lacked $A L K$ and NPM/ALK rearrangements.

\section{DISCUSSION}

IMT is classified with intermediate neoplasms in the current World Health Organization Histological Typing of Soft Tissue Tumors (16). Recent studies have identified chromosomal abnormalities occurring in a proportion of pulmonary and extrapulmonary IMTs, lending support to the concept of IMT as a neoplasm $(3-5,9,24-28)$. These recurrent abnormalities involve chromosome 2p21-24, are associated with $A L K$ deregulation, and are characterized by $A L K$ expression by immunohistochemistry (3-5). The understanding of the relationship between inflammatory pseudotumor and inflammatory pseudotumor-like neoplasms continues to evolve, although it is clear that both reactive and neoplastic processes have histologic similarities ( 1 , 7, 29-32).

Originally described in anaplastic large cell lymphoma, $A L K$ abnormalities identify a distinct subgroup of anaplastic large cell lymphomas with a favorable prognosis. Recent studies have reported the association of $A L K$ expression in IMT with a younger age at presentation $(4,5,7)$. Immunohistochemistry for $A L K$ expression, using both monoclonal and polyclonal antibodies, has previously correlated well with results of reverse transcriptase polymerase chain reaction, FISH, and conventional cytogenetics for detection of $A L K$ abnormalities (3,
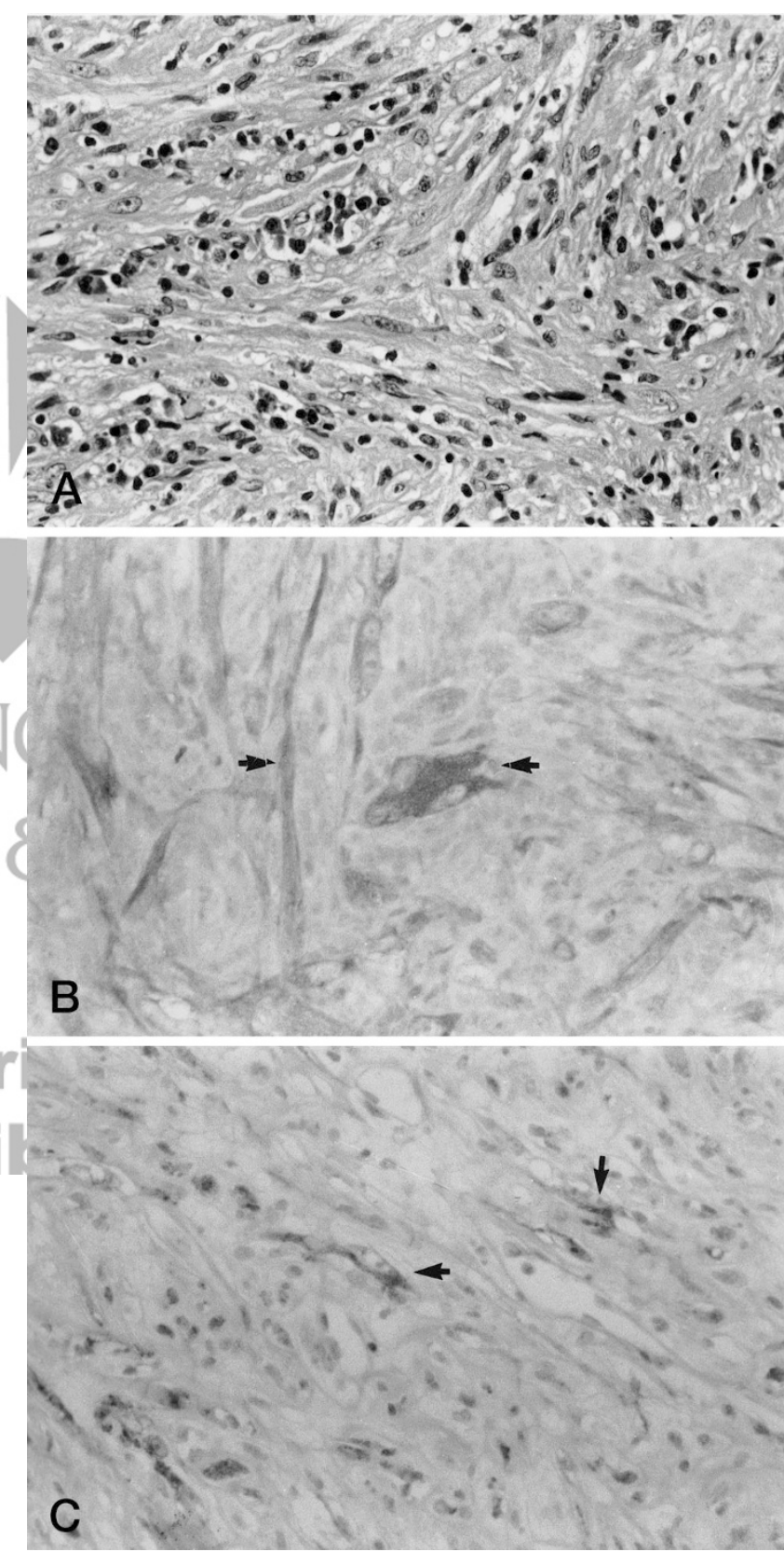

FIGURE 1. Inflammatory myofibroblastic tumor. A, inflammatory myofibroblastic tumor displays a proliferation of spindled fibroblasticmyofibroblastic cells in fascicles accompanied by an inflammatory infiltrate of plasma cells with variable lymphocytes and eosinophils (hematoxylin-eosin). B, ALK1 cytoplasmic reactivity (arrows) is present in spindle and ganglion-like cells (ALK1 immunohistochemistry). C, p80 cytoplasmic reactivity (arrows) is present in spindle and ganglion-like cells (p80 immunohistochemistry). 


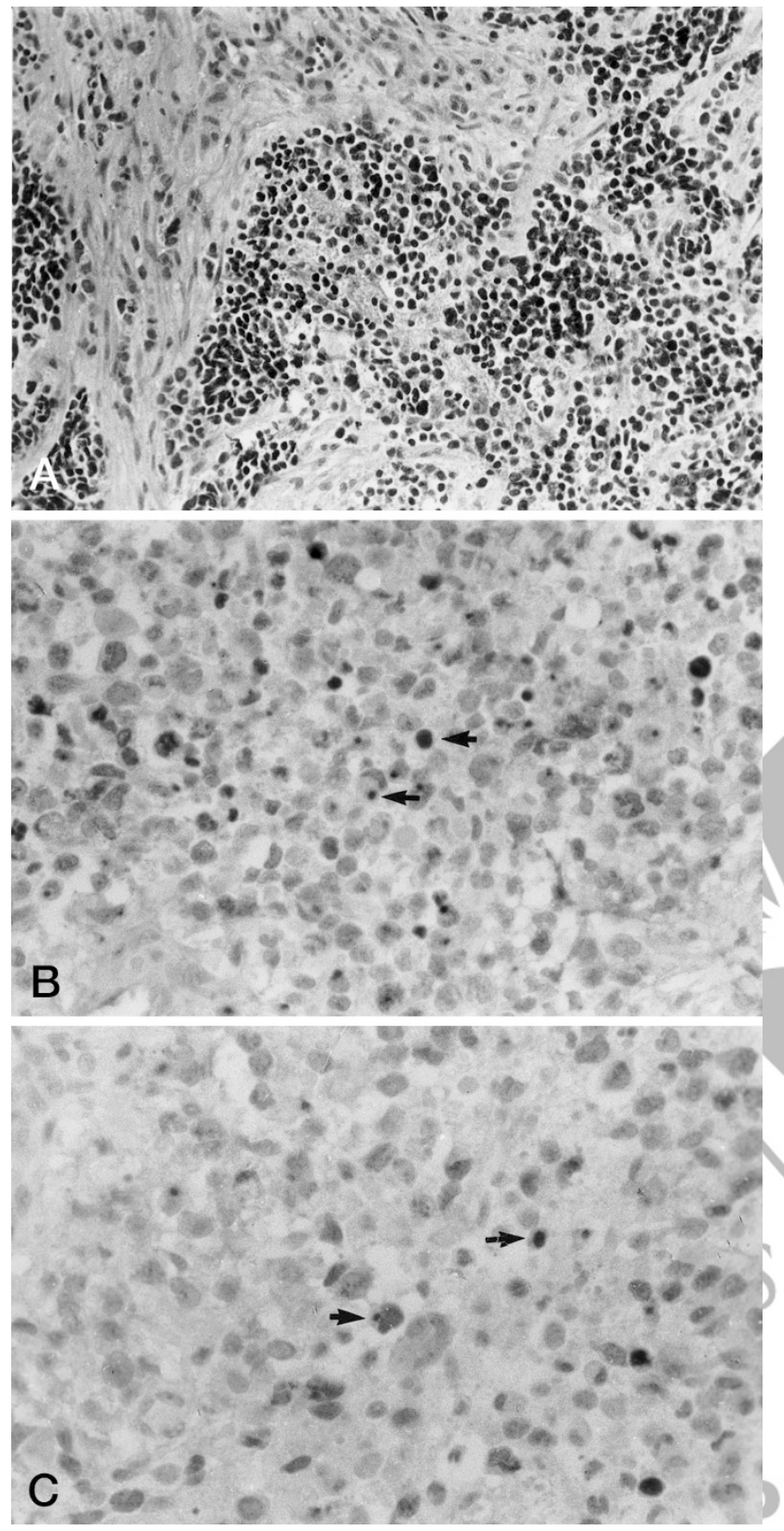

FIGURE 2. Alveolar rhabdomyosarcoma. A, alveolar rhabdomyosarcoma consists of small round tumor cells lining fibrovascular septa and floating in pseudoalveolar spaces (hematoxylineosin staining). B, ALK1 reactivity (arrows) with a distinctive dot-like cytoplasmic pattern (ALK1 immunohistochemistry). C, p80 reactivity (arrows) with a distinctive dot-like cytoplasmic pattern.

$5,11,14,33)$. The similar 2p23 abnormalities in IMT and anaplastic large cell lymphoma raise the question of whether the $A L K$ family of tumors includes other mesenchymal neoplasms, especially because $A L K$ tyrosine kinase gene expression has been found in cell lines from several tumor types $(12,15)$ and because neoplasms of fibroblasts and myofibroblasts encompass a large and histologically similar group of entities. An additional question is whether $A L K$ immunohistochemistry is useful for differential diagnosis or principally for detection of an $A L K$ abnormality.
TABLE 3. FISH in ALK1/p80-Positive Mesenchymal Tumors

\begin{tabular}{lccl}
\hline & \multicolumn{3}{c}{ FISH (No. of Cases) } \\
\cline { 2 - 4 } Diagnosis $(n)$ & $\begin{array}{c}\text { ALK Break-Apart } \\
\text { Probe Split }\end{array}$ & $\begin{array}{c}\text { NPM/ALK } \\
\text { Fusion }\end{array}$ & $\begin{array}{c}\text { Extra 2p23 } \\
\text { Copies }\end{array}$ \\
\hline IMT (3) & $3^{a}$ & 0 & 0 \\
ARMS (4) & $1^{b}$ & 1 & 2 (3-6 copies) \\
ERMS (2) & 0 & 1 & 1 (3 copies) \\
MPNST (2) & 0 & 1 & 0 \\
LMS (1) & 0 & 0 & $1(2$ copies) \\
MFH (1) & 0 & 0 & $1(2$ copies $)$ \\
\hline
\end{tabular}

IMT, inflammatory myofibroblastic tumor; ARMS, alveolar rhabdomyosarcoma; ERMS, embryonal rhabdomyosarcoma; MPNST, malignant peripheral nerve sheath tumor; LMS, leiomyosarcoma; MFH, malignant fibrous histiocytoma; NPM, nucleophosmin; FISH, fluorescence in situ hybridization.

${ }^{a}$ Two IMTs had classic splits, and one had a complex variant with 1-2 fusion and 2 red signals.

${ }^{b}$ One ARMS had a complex variant split signal with the ALK breakapart probe, which included three fusion and two red signals and a negative NPM/ALK signal.

Previous studies have shown that $A L K$ gene rearrangements and/or $A L K$ expression are found in anaplastic large cell lymphoma, IMT, and cell lines from neuroblastoma, neuroectodermal tumors, malignant melanoma, small cell lung carcinoma, and rhabdomyosarcoma (Table 4). Non-neoplastic central nervous system tissue also expresses $A L K$. The present study of IMT and other mesenchymal neoplasms demonstrated ALK1 and/or p80 reactivity in IMTs $(40 \%)$ and in rhabdomyosarcomas (19\%), malignant peripheral nerve sheath tumors (40\%), malignant fibrous histiocytomas (9\%), and leiomyosarcomas (10\%). These findings confirm those of previous studies, which have shown ALK1 immunohistochemical reactivity in $8-62 \%$ of IMTs and "inflammatory pseudotumors" $(3,5,7-9,34)$. The present study also confirmed the presence of $A L K$ and/or p80 expression in rhabdomyosarco-

TABLE 4. ALK Protein Expression by

Immunohistochemistry in Neoplastic and Normal

Tissues: Summary of 10 Series

\begin{tabular}{lcl}
\multicolumn{1}{c}{ Neoplasms Positive } & $\begin{array}{c}\text { No. } \\
\text { Positive/Total }\end{array}$ & \multicolumn{1}{c}{$\begin{array}{c}\text { Reference } \\
\text { No. }\end{array}$} \\
\hline $\begin{array}{l}\text { Anaplastic large cell } \\
\text { lymphoma }\end{array}$ & $137 / 309$ & $2,3,11,13-15$ \\
$\begin{array}{l}\text { Inflammatory } \\
\text { myofibroblastic tumor }\end{array}$ & $28 / 68$ & Present study, 4, 5 \\
$\begin{array}{l}\text { Neuroblastoma } \\
\text { Rhabdomyosarcoma }\end{array}$ & $2 / 5$ & 15 \\
$\begin{array}{l}\text { Malignant peripheral nerve } \\
\text { sheath tumor }\end{array}$ & $7 / 34$ & $\begin{array}{l}\text { Present study, 12, 15 } \\
\text { Leiomyosarcoma } \\
\begin{array}{l}\text { Malignant fibrous } \\
\text { histiocytoma }\end{array}\end{array}$ \\
\end{tabular}

Normal tissues reportedly positive: cerebral cortex, hypothalamus, cerebellum, basal ganglia, thalamic nuclei (12). Neoplasms reportedly negative (present study, 2, 11-13): lymphomas other than ALCL, Hodgkin's disease, lymphomatoid papulosis, astrocytoma, glioma, glioblastoma, medulloblastoma, various carcinomas, germ cell tumors, Wilms' tumor, liposarcoma, malignant rhabdoid tumor, fibrosarcoma, synovial sarcoma, carcinoid, pheochromocytoma, thymoma, melanoma, others. 
mas, especially the alveolar type, and identified other mesenchymal neoplasms with $A L K$ expression. Correlation of the immunohistochemical findings with FISH probes for $A L K$ and NPM/ALK yielded interesting evidence of ALK rearrangements or extra copies of 2p23 in ALK1-positive non-IMTs. All of three IMTs had either classic ALK split signals or a complex variant fusion signal. The other nine ALK1 and/or p80-reactive mesenchymal tumors analyzed by FISH displayed either extra copies of $2 \mathrm{p} 23$ in five cases or $A L K$ rearrangements, with an $N P M / A L K$ fusion in three cases and a variant $A L K$ fusion in one case; one case could not be analyzed. Among the alveolar rhabdomyosarcomas, there was an association between the cytoplasmic dot-like pattern of ALK1 and p80 immunohistochemical staining and extra copies of $2 \mathrm{p} 23$. The recent study by Cook and colleagues (8) did not demonstrate $A L K$ expression in nodular fasciitis, desmoids, or gastrointestinal stromal tumors. Lawrence and colleagues (4) reported that $A L K$ was not expressed in nodular fasciitis, inflammatory liposarcoma, inflammatory leiomyosarcoma, or angiomatoid malignant fibrous histiocytoma.

Oncogenesis subsequent to translocations involving the $A L K$ gene occurs as a result of constitutive expression and activation of $A L K$, with abnormal phosphorylation of cellular substrates. Based on studies of anaplastic large cell lymphoma and IMT, a variety of genes are capable of derregulating $A L K$. A single fusion partner has not been found in ALK-positive anaplastic large cell lymphomas; rather, a variety of fusion partners has been identified, including NPM, clathrin, nonmuscular tropomyosin (TPM3), or TRK-fused gene (TFG). Previous studies of $A L K$ expression in anaplastic large cell lymphoma have shown recurrent characteristic localization patterns for ALK protein associated with specific $A L K$ fusion proteins (11-13). The variant fusions give rise to different $A L K$ immunohistochemical staining patterns than the typical nuclear or nuclear and cytoplasmic staining seen with the $\mathrm{t}(2,5)(\mathrm{p} 23$; q35) $N P M-A L K$ fusion protein. The most common pattern of $A L K$ expression seen in the variant translocations is diffuse cytoplasmic staining without a significant nuclear component. The $T P M-A L K$ fusion genes found in IMT and anaplastic large cell lymphoma were associated with intense, predominantly cytoplasmic staining $(4,35)$. In addition to identifying the TPM3-ALK and TPM4-ALK fusion genes in IMT, Lawrence and colleagues (4) identified the possibility of at least two alternative $A L K$ fusion mechanisms in IMT, resulting in predominantly cytoplasmic (3 cases) or predominantly nuclear (1 case) localization. ALK1-staining patterns in IMTs have recently been described as diffuse cytoplasmic, granular cytoplasmic, or nuclear membranous, with the diffuse cytoplasmic pattern occurring most frequently (8). The possibility exists that multiple mechanisms may result in $A L K$ deregulation; for example, point mutations involving the $A L K$ gene could also cause overexpression and abnormal trafficking of $A L K$ between the nucleus and cytoplasm. Whether clear-cut molecular-morphologic correlates will emerge is a question of great interest.

The IMTs in our study showed a diffuse cytoplasmic staining pattern, which was also observed in the $A L K$-positive malignant peripheral nerve sheath tumors, malignant fibrous histiocytomas, and leiomyosarcomas. Three of the alveolar rhabdomyosarcomas showed a characteristic dot-like pattern of cytoplasmic staining, two of these cases had additional copies of $2 \mathrm{p} 23$, and one had a variant $A L K$ fusion. This suggests that not only a specific fusion gene, but also other mechanisms can result in ALK overexpression in neoplasms with a variety of cytogenetic abnormalities. Alveolar rhabdomyosarcoma is often associated with a recurrent translocation involving the FKHR gene on chromosome 13q14 and the $P A X 3$ gene at $2 \mathrm{q} 35$ or $P A X 7$ gene on $1 \mathrm{p} 36$ (36). Less is known about the cytogenetic abnormalities in malignant peripheral nerve sheath tumor, malignant fibrous histiocytoma, or leiomyosarcoma. The data from this study suggest that there may be a subset of mesenchymal neoplasms that have in common abnormalities resulting from ALK deregulation and overexpression.

In this study, both the monoclonal antibody for ALK1 and the polyclonal antibody p80 were used to evaluate $A \bar{L} \bar{K}$ expression. Overall, the sensitivities of these antibodies was comparable, although p80 detected positive staining in one IMT and two malignant peripheral nerve sheath tumors that were nonreactive with the ALK1 antibody. Conversely, ALK1 detected ALK expression in one case of rhabdomyosarcoma that was nonreactive with the p80 antibody. Overall, the ALK1 antibody staining was easier to interpret, with a cleaner background in comparison to p80, as reported by previous investigators $(12,33)$. As in our previous study, the immunohistochemical expression of ALK1 and p80 was strongly associated with structural or numerical abnormalities of the $A L K$ region on chromosome $2 \mathrm{p} 23$ (5).

Although the ALK immunoreactivity and cytogenetic abnormalities in rhabdomyosarcoma, malignant peripheral nerve sheath tumor, leiomyosarcoma, and malignant fibrous histiocytoma are as yet incompletely characterized as to numerical or structural chromosomal abnormalities involving 2 p23 or as to $A L K$ deregulation by other means, the findings in this study support the concept of $A L K$ involvement in a larger group of mesenchymal neoplasms, some of which have other known clonal abnormalities. Immunohistochemistry for ALK1 
and p80 is useful when positive as an indicator of 2 p23 rearrangement in IMT but must be interpreted in the context of histologic and other clinicopathologic data if used as an adjunct for differential diagnosis. Although the frequency of ALK1 immunoreactivity in IMT ranges from $36-60 \%$ (5, 8), ALK1 and p80 reactivity provide evidence to support the diagnosis of IMT, with the caveats that the typical histologic features are present and that anaplastic large cell lymphoma has been excluded. When negative, careful consideration of alternative diagnoses, including nonneoplastic or inflammatory pseudotumors, is critical, although a significant percentage of IMTs will not exhibit ALK1 and p80 expression. Because a small proportion of various sarcomas in this study demonstrated ALK1 and p80 reactivity, further investigation of the role of $A L K$ deregulation in mesenchymal neoplasms may yield information of potential biologic and therapeutic significance.

Acknowledgments: The authors thank Samantha Farr, Michelle Gonzalez, and Kristi Herrin for their secretarial expertise.

\section{REFERENCES}

1. Coffin CM, Watterson J, Priest JR, et al. Extrapulmonary inflammatory myofibroblastic tumor (inflammatory pseudotumor). A clinicopathologic and immunohistochemical study of 84 cases. Am J Surg Pathol 1995;19:859-72.

2. Nakamura S, Shiota M, Nakagawa A, et al. Anaplastic large cell lymphoma: a distinct molecular pathologic entity: a reappraisal with special reference to $\mathrm{p} 80(N P M / A L K)$ expression. Am J Surg Pathol 1997;21:1420-32.

3. Griffin CA, Hawkins AL, Dvorak C, et al. Recurrent involvement of 2p23 in inflammatory myofibroblastic tumors. Cancer Res 1999;59:2776-80.

4. Lawrence B, Perez-Atayde A, Hibbard MK, et al. TPM3-ALK and TPM4-ALK oncogenes in inflammatory myofibroblastic tumors. Am J Pathol 2000;157:377-84.

5. Coffin CM, Patel A, Perkins SL, et al. ALK1 and p80 expression and chromosomal rearrangements involving $2 \mathrm{p} 23$ in inflammatory myofibroblastic tumor. Mod Pathol 2001;14: 569-76.

6. Cheuk W, Hill RW, Bacchi C, et al. Hypocellular anaplastic large cell lymphoma mimicking inflammatory lesions of lymph nodes. Am J Surg Pathol 2000;24:1537-43.

7. Chan JK, Cheuk W, Shimizu M. Anaplastic lymphoma kinase expression in inflammatory pseudotumors. Am J Surg Pathol 2001;25:761-8.

8. Cook JR, Dehner LP, Collins M, et al. Anaplastic lymphoma kinase (ALK) expression in the inflammatory myofibroblastic tumor: a comparative immunohistochemical study. Am J Surg Pathol 25:1364-71.

9. Yousem SA, Shaw H, Cieply K. Involvement of $2 \mathrm{p} 23$ in pulmonary inflammatory pseudotumors. Hum Pathol 2001;32: 428-33.

10. Shiota M, Fujimoto J, Takenaga $\mathrm{M}$, et al. Diagnosis of $\mathrm{t}(2$; 5) (p23;q35)-associated Ki-1 lymphoma with immunohistochemistry. Blood 1994;84:3648-52.

11. Pittaluga S, Wiodarska I, Pulford K, et al. The monoclonal antibody ALK1 identifies a distinct morphological subtype of anaplastic large cell lymphoma associated with 2p23/ALK rearrangements. Am J Pathol 1997;151:343-51.

12. Pulford K, Lamant L, Morris SW, et al. Detection of anaplastic lymphoma kinase $(A L K)$ and nucleolar protein nucleophosmin (NPM)-ALK proteins in normal and neoplastic cells with the monoclonal antibody ALK1. Blood 1997;89:1394404.

13. Falini B, Bigerna B, Fizzotti M, et al. ALK expression defines a distinct group of T/null lymphomas ("ALK lymphomas") with a wide morphological spectrum. Am J Pathol 1998;153: 875-86.

14. Cataldo KA, Jalal SM, Law ME, et al. Detection of $\mathrm{t}(2 ; 5)$ in anaplastic large cell lymphoma: comparison of immunohistochemical studies, FISH, and RT-PCR in paraffinembedded tissue. Am J Surg Pathol 1999;23:1386-92.

15. Lamant L, Pulford K, Bischof D, et al. Expression of the $A L K$ tyrosine kinase gene in neuroblastoma. Am J Pathol 2000; 156:1711-21.

16. Weiss SW. Histologic typing of soft tissue tumors. 2nd ed. New York: Springer-Verlag, 1994.

17. Newton WA Jr, Gehan EA, Webber BL, et al. Classification of rhabdomyosarcomas and related sarcomas. Pathologic aspects and proposal for a new classification-an Intergroup Rhabdomyosarcoma Study. Cancer 1995;76:1073-85.

18. Eyden BB, Banerjee SS, Harris M, Mene A. A study of spindle cell sarcomas showing myofibroblastic differentiation. Ultrastruct Pathol 1991;15:367-78.

19. Smith DM, Mahmoud HH, Jenkins JJ, Rao B, Hopkins KP, Parham DP. Myofibrosarcoma of the head and neck in children. Pediatr Pathol Lab Med 1995;15:403-18.

20. Montgomery E, Goldblum JR, Fisher C. Myofibrosarcoma: a clinicopathologic study. Am J Surg Pathol 2001;25:219-28.

21. Coffin CM, Jaszcz W, O'Shea PA, et al. So-called congenitalinfantile fibrosarcoma: does it exist and what is it? Pediatr Pathol 1994; 14:133-50.

22. Coffin CM, Rulon J, Smith L, et al. Pathologic features of rhabdomyosarcoma before and after treatment: a clinicopathologic and immunohistochemical analysis. Mod Pathol 1997; 10:1175-87.

23. Hussong JW, Brown M, Perkins SL, et al. Comparison of DNA ploidy, histologic, and immunohistochemical findings with clinical outcome in inflammatory myofibroblastic tumors. Mod Pathol 1999;12:279-86.

24. Treissman SP, Gillis DA, Lee CL, et al. Omental-mesenteric inflammatory pseudotumor. Cytogenetic demonstration of genetic changes and monoclonality in one tumor. Cancer 1994;73:1433-7.

25. Hojo H, Newton WA Jr, Hamoudi AB, et al. Pseudosarcomatous myofibroblastic tumor of the urinary bladder in children: a study of 11 cases with review of the literature. An Intergroup Rhabdomyosarcoma Study. Am J Surg Pathol 1995;19:1224-36.

26. Snyder CS, Dell'Aquila M, Haghighi P, et al. Clonal changes in inflammatory pseudotumor of the lung: a case report. Cancer 1995;76:1545-9.

27. Sciot R, Dal Cin P, Fletcher CD, et al. Inflammatory myofibroblastic tumor of bone: report of two cases with evidence of clonal chromosomal changes. Am J Surg Pathol 1997;21: $1166-72$.

28. Su LD, Atayde-Perez A, Sheldon S, et al. Inflammatory myofibroblastic tumor: cytogenetic evidence supporting clonal origin. Mod Pathol 1998;11:364-8.

29. Coffin CM, Humphrey PA, Dehner LP. Extrapulmonary inflammatory myofibroblastic tumor: a clinical and pathological survey. Semin Diagn Pathol 1998;15:85-101.

30. Dehner LP. The enigmatic inflammatory pseudotumours: the current state of our understanding, or misunderstanding. J Pathol 2000;192:277-9. 
31. Dehner LP, Coffin CM. Idiopathic fibrosclerotic disorders and other inflammatory pseudotumors. Semin Diagn Pathol 1998;15:161-73.

32. Gomez-Roman JJ, Sanchez-Velasco P, Ocejo-Vinyals G, et al. Human herpesvirus- 8 genes are expressed in pulmonary inflammatory myofibroblastic tumor (inflammatory pseudotumor). Am J Surg Pathol 2001;25:624-9.

33. Shiota M, Nakamura S, Ichinohasama R, et al. Anaplastic large cell lymphomas expressing the novel chimeric protein p80NPM/ALK: a distinct clinicopathologic entity. Blood 1995; 86:1954-60.
34. Cheuk W, Chan JK, Shek TW, et al. Inflammatory pseudotumor-like follicular dendritic cell tumor: a distinctive low-grade malignant intra-abdominal neoplasm with consistent Epstein-Barr virus association. Am J Surg Pathol 2001;25:721-31.

35. Lamant L, Dastugue N, Pulford K, et al. A new fusion gene TPM3-ALK in anaplastic large cell lymphoma created by a $(1 ; 2)(\mathrm{q} 25 ; \mathrm{p} 23)$ translocation. Blood 1999;93:3088-95.

36. Barr FG, Chatten J, D'Cruz CM, et al. Molecular assays for chromosomal translocations in the diagnosis of pediatric soft tissue sarcomas. JAMA 1995;273:553-7.

\section{Book Review}

\section{Robboy SL, Anderson MC, Russell P: Pathology of the Female Reproductive Tract, 929 pp, London, Churchill Livingstone, 2002 (\$250.00).}

'When in the course of human events it becomes necessary' (with an apology to Thomas Jefferson) to come up with a major new textbook of gynecologic pathology, the most important prerequisite is the confluence of minds: that of a firstclass publisher experienced in such matters, and that of team of enthusiastic authors/editors willing to see to it that the project is completed in due time. Preferably, the putative editors should have a respectable track record. In the present case it helped that all three editors have written extensively on gynecologic pathology, and it definitely does not hurt that/they have authored chapters for books that could now be considered as a competition of their own. For the record I should mention that many years ago I reviewed Dr. Russell's book on the pathology of the ovaries, which is now in part incorporated in the present book; I still think that it is one of best books of ovarian pathology ever written.

This voluminous book is a physically beautiful piece of art reflecting the know-how of both the British publisher and the transcontinental team of editors and contributors. In contrast to other major textbooks of gynecologic pathology, its illustrations are almost all in color and, all other things being equal, that is an enormous advantage - pathology is still in effect a visual discipline. The editors deserve compliments for assembling such a cornucopia of gross and microscopic figures, and the publishers are to be congratulated for rendering them in print so brilliantly.

The beauty of the illustrations should, however, not detract one from the well-written and masterfully edited text. By all standards it is comprehensive, informative, and replete with useful data and diagnostic hints. In contrast to the verbosity of some other texts, this one is rather lapidary. For my part, I find it not only more desirable but also more admirable-concise writing requires more effort than semiautomatic dictation of whatever comes to one's mind. The present text strikes the right balance between being comprehensive and being to the point. It is just right for a busy pathologist swamped in his or her daily practice with tons of surgical material. A structured and systematic approach to each entity, applied throughout the book, will make it also attractive to novices who may decide to read it cover to cover over a period of several moths or even years. The tables dealing with the differential diagnosis of closely related or morphologically similar entities are a feature worth mentioning, and one regrets only that the book does not contain more of them. Tabular presentations of immunophenotypes of various tumors are yet another notable attraction. The references are well chosen and up to date.

The review copy of this book reached me 6 months after it appeared in print. One of the possible reasons, as I learned from talking with Dr. Robboy, is that the demand exceeded the initial supply, surpassing the publisher's expectations. From what I know about medical publishing, I would predict that the demand will remain strong, and I predict that many more copies of this wonderful book will be sold over the next few years all over the world.

\section{Ivan Damjanov}

University of Kansas School of Medicine, Kansas City, Kansas 